Article

\title{
The Asian Values of Guānxì as an Economic Model for Transition toward Green Growth
}

\author{
Yongrok Choi iD \\ Department of International Trade, Inha University, Inharo100, Nam-gu, Incheon 402-751, Korea; \\ yrchoi@inha.ac.kr; Tel.: +82-32-860-7760; Fax: +82-32-876-9328
}

Received: 21 May 2018; Accepted: 22 June 2018; Published: 25 June 2018

\begin{abstract}
Most Asian countries are experiencing escalating air pollution and other environmental challenges. Many political measures, such as regulations and promotional subsidies, have not proved effective or efficient due to a lack of governance. The reason for this may come from the historical and cultural background of government-led economies. Due to the top-down approach to sustainable development, most private sector companies, as well as the general population, do not participate voluntarily in meeting these new challenges. In order for these Asian countries to become leaders in the new global trend towards green growth, this paper examines the Asian values of guānxì to facilitate the interrelationship between public and private sectors, and proposes an Asian public-private partnership model with five structural principles, three functional propositions, and seven procedural factors. Using these governance elements, Asian governments should create, maintain, and utilize the progression of guānxì from acquaintance via trust to loyalty. Through this stepwise approach, Asian governments could construct an innovative virtuous circle to create value based on network management, which is the ultimate paradigm of sustainable development.
\end{abstract}

Keywords: Asian value; Asian model; loyalty; guānxì; public-private partnership (PPP)

\section{Introduction}

\subsection{Background of Climate Change in the Policies in Asia}

The United Nations Framework Convention on Climate Change (UNFCCC) is an international environmental treaty that was adopted on 9 May 1992 in order to overcome global climate change and the resultant global warming. Since its first Conference of the Parties (COP) meeting in 1995, it has become the major platform for the nations of the world to mitigate the undesirable effects of climate change, as well as to simultaneously promote sustainable development. Over time, a series of COP meetings resulted in an outstanding workable mechanism for the sustainable engagement of global society to reduce greenhouse gas (GHG) emissions. In particular, the third COP meeting in Kyoto accomplished the most impressive mission of implementing a flexible mechanism that can measure, monitor, and manage GHG emissions in a market-oriented mechanism comprising the international emissions trading scheme (ETS), the clean development mechanism (CDM), and joint implementation (JI). The flexible structure of the Kyoto Protocol facilitates a coordinated response to global warming by allowing the participating members-38 developed countries and the European Union - to trade their emissions in assigned amount units (AAUs), or "allowances" for short [1] (p. 11).

ETS is the basic platform for all of the participating economic entities to decrease their GHG emissions to below the scheme's mandatory level and then sell their available allowances to other economic agents that produced more than the mandatory goal assigned by their government. If agents cannot reduce their GHG emissions, they may cooperate with economic agents in other developed countries to invest in the development of green or clean technology to reduce GHGs and obtain 
allowances in other developed countries (JI) or even in developing countries (CDM). This flexible mechanism worked well, at least during the first stage of the Kyoto Protocol over the years 2008 through 2012. While this mechanism forms a major cornerstone toward sustainable development or green growth, it has inherent limits in expanding its mechanism, due to the top-down approach to reducing GHG emissions adopted by the selected group of governments in Annex I. Many governments and their regulated leading companies made complaints about advantage being taken of this top-down type of sacrifice by free riders, which placed costly new burdens on the participating parties. Due to these conflicts, the Kyoto Protocol could no longer proceed to its second stage.

Meanwhile, climate change has become a much more serious challenge for all humankind, and the extra burden cannot be handled by a group of developed countries only. This was the background of the Paris agreement toward the post-2020 climate change regime. The Paris Agreement in 2015 formed another great milestone toward sustainable development worldwide. Based on a bottom-up marketand performance-oriented mechanism, the new climate regime in the Paris Agreement provides optimal path control for moving toward the below $2{ }^{\circ} \mathrm{C}$ target from pre-industrial levels by substantially decreasing GHG emissions [2]. Of the 197 members of the COP, 113 ratified the Paris Agreement, implying that $79 \%$ of global GHG emissions will be sustainably managed under the post-2020 climate regime [3]. Compared with the Kyoto Protocol's 22\% coverage for GHG emissions, this was an outstanding achievement in terms of quantitative as well as qualitative agreement on global climate change policy [3]. This global participation based on voluntary commitments on GHG emissions created great hopes for humankind to enter a new era of sustainable development. Unfortunately, the withdrawal of the USA from the Paris Agreement under the new Trump administration will result in $\mathrm{CO}_{2}$ emissions that are 13 gigatons (Gt) higher than the original $56 \mathrm{Gt}$ target (a $23 \%$ increase) and could pose a disastrous global dilemma, because this new mission needs time to focus efforts on new targets; however, global warming will not wait for the remaining countries to adjust to this new situation. In order to decrease $\mathrm{CO}_{2}$ by $1 \mathrm{Gt}$, all the cars in the EU would have to cease driving completely for one year, which makes the situation almost unimaginable when we include an additional reduction target of $56 \mathrm{Gt}$ to compensate for the withdrawal of the United States.

\subsection{Political Challenges of Sustainable Governance in Asia}

Nonetheless, we should find a way toward the 2020 new climate regime, because sustainable development is not optional any more, but now represents a survival kit for all. Until the mid-2000s, the Chinese government, as a representative developing country, insisted that the developed countries should make greater efforts to reduce GHGs and contribute more funds to developing countries for GHG adaptation. However, China no longer insists on such conditional adaptation on the part of developed countries, because these survival strategies now apply to all nations. As shown in Figure 1, China and other northeast Asian countries are experiencing widespread severe air pollution, with particulate matter (PM) values of 2.5 or less, which is life-threatening toxic smog. More than three million people per year are dying directly and indirectly from this air pollution, and more than two thirds of Beijing and other large cities in China are experiencing this terrible PM smog. Even in Korea, many people are suffering diverse disease due to this PM smog. Figure 1 shows that these northeast Asian countries are suffering genuine PM smog disasters all too frequently. Therefore, for these countries, as well as for other developing economies, sustainable development is no longer optional. The priority of a healthy existence is a top challenge for the future. In 2016, Xi Jinping, the leader of China, pronounced a new era of "Ecological Civilization" for China, which means that the Chinese dream of becoming the leading global economy should begin with the nation acting as a trendsetter in overcoming diverse environmental challenges. The Chinese government has already signed a treaty with the Korean government to cooperate in facing regional air pollution challenges. In particular, the northeast Asian countries are very close, not only in the similarity of their economic structures and leading industries, but also in the cooperative management of interdependent regional supply chains. It is clear that these environmental challenges-illustrated by GHG smog being carried by wind from 
northeast Asia to Japan—should be handled through interdependent cooperation, because of these simultaneously occurring environmental disasters.

To find any solutions for these regional environmental challenges, we need to adopt different perspectives compared with the traditional Western-style approaches. None of the existing theories based on the traditional paradigm can solve the environmental or sustainability challenges appropriately, because of this strong interdependence among the economic activities in the region and the resulting environmentally undesirable outcomes. The traditional paradigm of economics is based on cost-saving and efficiency: minimizing inputs and maximizing outputs. By the same token, traditional business management is based on the paradigm of profit maximization. These social practices are based on competition-oriented zero-sum game rules. In order to maximize economic efficiency, we should have ceteris paribus conditions, because one economic agent cannot increase its efficiency unless other economic agents give up something to achieve optimal Pareto equilibrium. In business, any company should act to maximize its profits using diverse marketing promotion strategies. In this push marketing paradigm, the company does not care about the interests of other parties at all; the "beggar-my-neighbor" approach. Unfortunately, these traditional theories cannot be sustainable, because the other interest groups are not satisfied with the maximization of one specific agent's profit. For example, Toyota pushed its outsourcing companies to deliver high-quality parts at lower costs in 2009; due to the ever-increasing pressure for lower costs, the outsourcing companies delivered faulty floor mats under accelerator pedals, causing these pedals to stick and accelerate the car, and resulting in huge claims across the world because of malfunctioning accelerator systems. The company could gain short-term profit maximization, but this was not sustainable, due to these squeezing strategies of other partners, such as outsourcing companies, workers, and consumers. Stakeholders such as consumers, outsourcing companies, and company employees should not be targets of profit maximization, but rather partners to create new sources of value in the long term [1].

Therefore, instead of targeting visible profits in the short run, companies and policy-makers should aim toward more harmonized network cooperation among all related interest groups. Through the proactive participation of these stakeholders, the company and/or policy-makers can create value in the long run, which is much more important in this interdependent society. This implies that the entire traditional paradigm of maximization-oriented approaches based on competitive mechanisms should be shifted towards the new paradigm of sustainable development. This can be summarized as value creation based on network management. Instead of maximizing "my" portion of the pie under traditional economic activities, harmonizing value sharing for sustainable performance could create a larger pie for all participants, who will therefore be happy to participate voluntarily to create value in these innovative ways. This is the spirit of the Paris Agreement under the 2020 new climate regime. It is not easy to achieve this kind of value creation in sustainable ways, and thus governance becomes much more important in this new paradigm of sustainable development. Here, governance is defined as a workable mechanism for sustainable performance. In order to promote good governance in shifting from having the largest possible piece of the pie at equilibrium (the traditional paradigm) toward the innovative and creative economy (the new paradigm), the most important task is to identify and promote governance factors such as mutual trust and loyalty.

In particular, the values of "trust" and "loyalty" are much more inherent in Asian countries, and thus this research aims to find out what kinds of Asian values could be important for these Asian countries to become trendsetters under the new 2020 Paris climate regime. Frankly speaking, there are numerous papers that aim to find solutions for climate change and global warming using tools from the traditional paradigm in developed countries, such as the Porter hypothesis, Kuznets curves, J-curve theory, etc. Unfortunately, even the combination of these approaches is not adequate to propose optimal path control toward sustainable development, because all of these approaches are based on the maximization of efficiency, or on integrated profits from the perspectives of stockholders or policy-makers. Thus, these researchers cannot propose creative or innovative ways to address environmental challenges. 


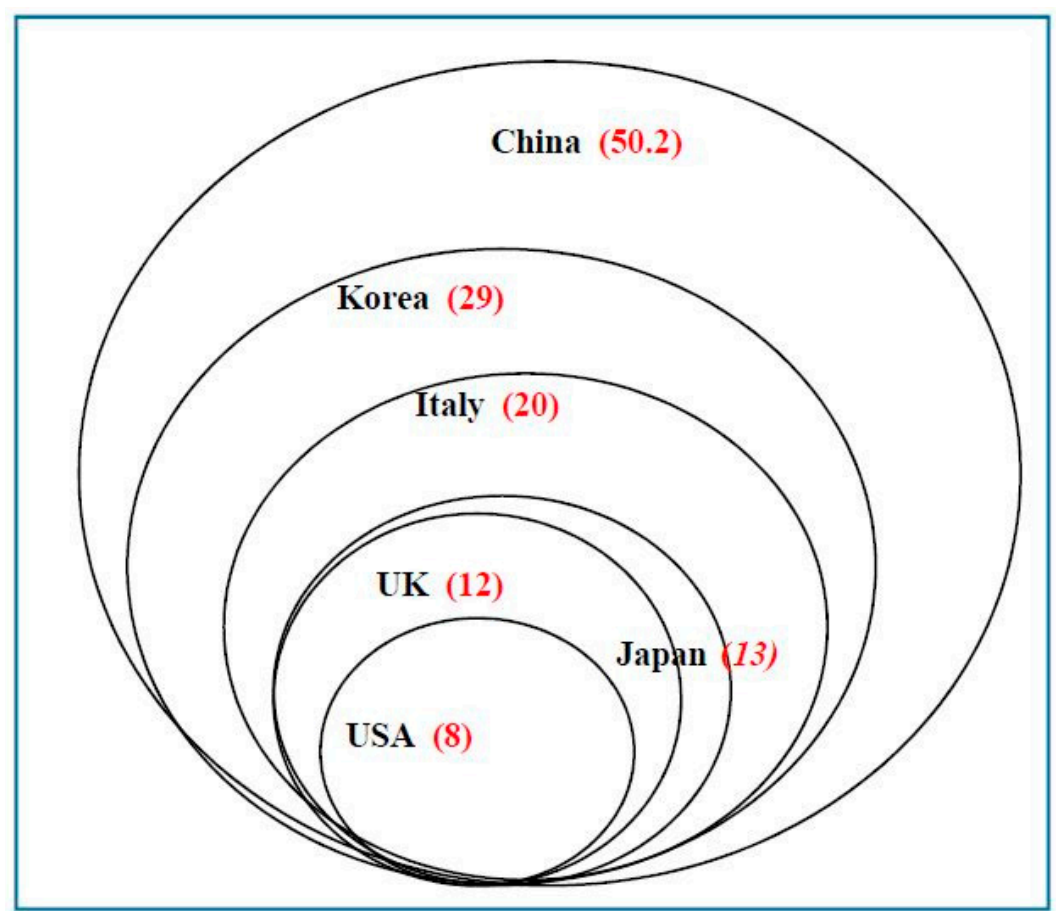

Figure 1. Particulate matter (PM) 2.5 air quality of major countries (2015; unit: $\left.\mu \mathrm{g} / \mathrm{m}^{3}\right)$.

Therefore, in order to propose a new way of thinking toward sustainable development grounded in Asian values, this research focuses on new propositions based on the Asian way of harmonizing public-private relational governance to create value. That is the public-private partnership (PPP) based on Asian values and Asian ways of network management. In this research, we focus on the critical factors of this new PPP approach using the integrated new paradigm developing across the social sciences in terms of structural, functional, and procedural approaches. Section 2 will analyze the conceptual characteristics of trust and loyalty from the Asian value perspective. Based on the Asian value of loyalty, Section 3 will propose diverse governance factors for the sustainable performance of PPP in the Asian model perspective. Section 4 concludes with the implications of Asian values and Asian models from the perspective of economic transitions.

\section{Conceptual Characteristics of Asian Values: Guānxì and Loyalty}

\subsection{Sustainable Governance Challenges of Asian Environmental Policies}

The abysmal Fukushima nuclear power plant accident occurred on 11 March 2011. Seven years later, due to this nuclear incident, most major countries have changed their paradigm toward clean and renewable energy. Switzerland's nuclear energy share is 35\% at present, but after several referendums from 1979, the country finally declared in 2017 that no more new nuclear plants would be built from 2019, and aimed step-by-step to achieve a zero-nuclear society by 2034. Germany had 17 nuclear power plants in 2011, but declared a zero-nuclear society by 2022. Italy also initiated a zero-nuclear policy by 2022. Of course, Japan is also considering a significantly lower share of nuclear power. Certainly, due to the Fukushima disaster, an increased renewable energy share has become core to the future challenge. New investment in clean energy reached the record figure of $\$ 360.3$ billion in 2015, followed by $\$ 324.6$ billion in 2016, and $\$ 333.5$ billion in 2017. As shown in Figure 2, most of this investment went to renewable energy in 2016 [4]. 


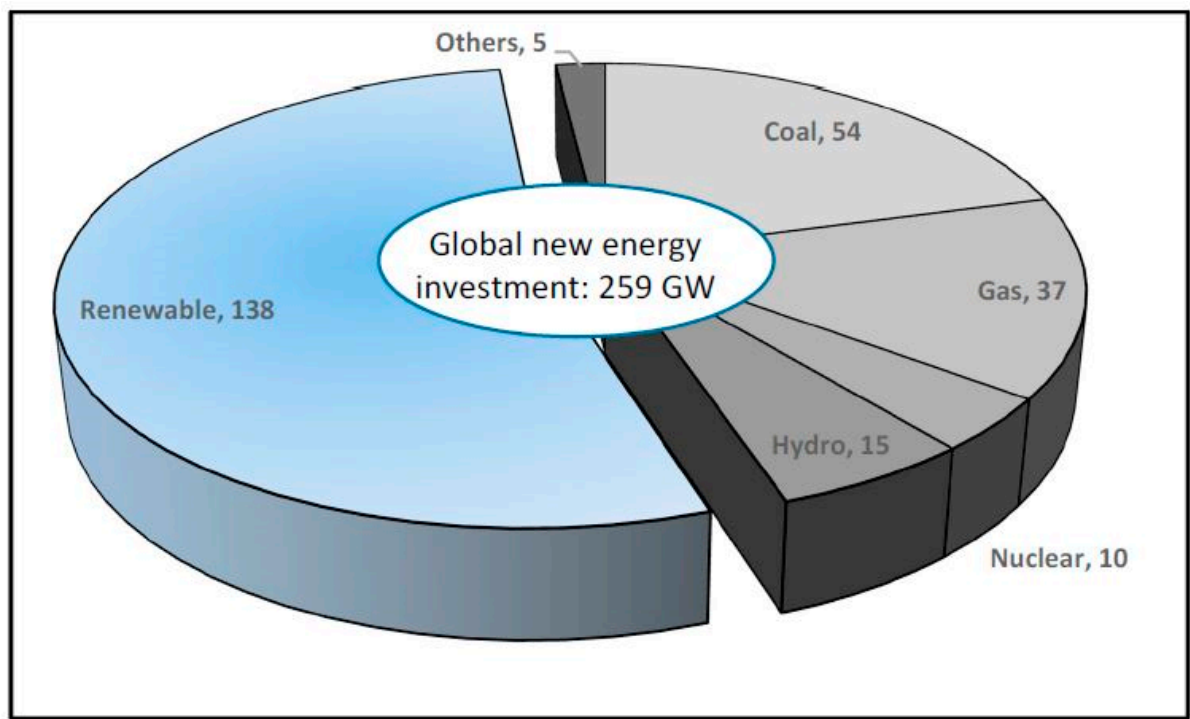

Figure 2. Net power-generating capacity investments in 2016 (unit: GW) [5].

Figure 2 shows the overall mix of global power generation investment. Nuclear power plants took only a 3\% share of new global energy investment in 2016, while renewable energy excluding large hydro made up the majority of the new capacity added globally. The $138 \mathrm{GW}$ of new wind, solar, biomass and waste, geothermal, and small hydro plants were equivalent to $53 \%$ of new additions for all generating technologies [5]. Due to this transition toward renewable energy, the supply costs of these sources has decreased sharply. For example, the solar industry has shown a 50-fold growth rate from 6 GW in 2006 to 303 GW in 2016 (Figure 3, [6]). Due to the rapidly increasing investments in solar energy, the supply cost of solar energy decreased sharply to 5 cents per kilowatt, just 1/130 of the cost 40 years ago, as shown in Figure 4 [7]. Based on this booming trend toward solar energy, it is expected to have grid parity by 2022 [8].

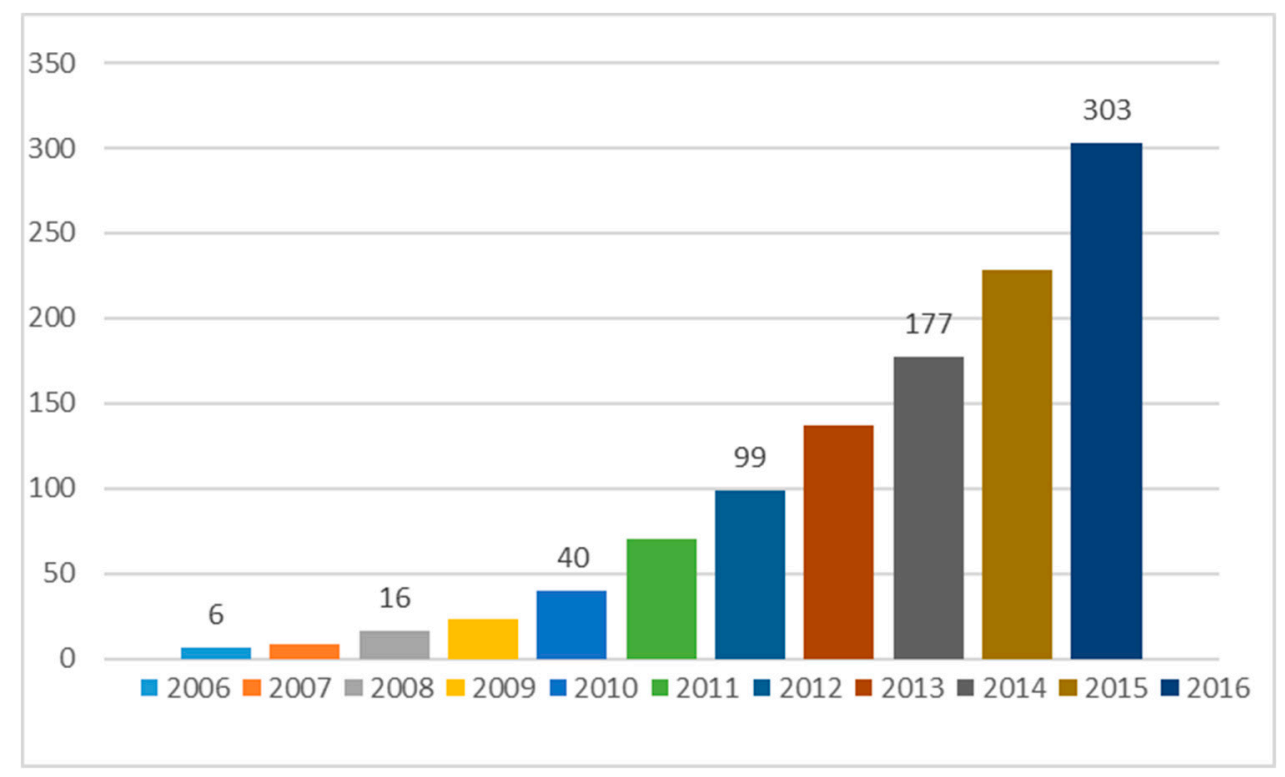

Figure 3. Solar PV (photovoltaic system) global capacity, 2006-2016. Source: Renewables 2017 Global Status Report [6]. 


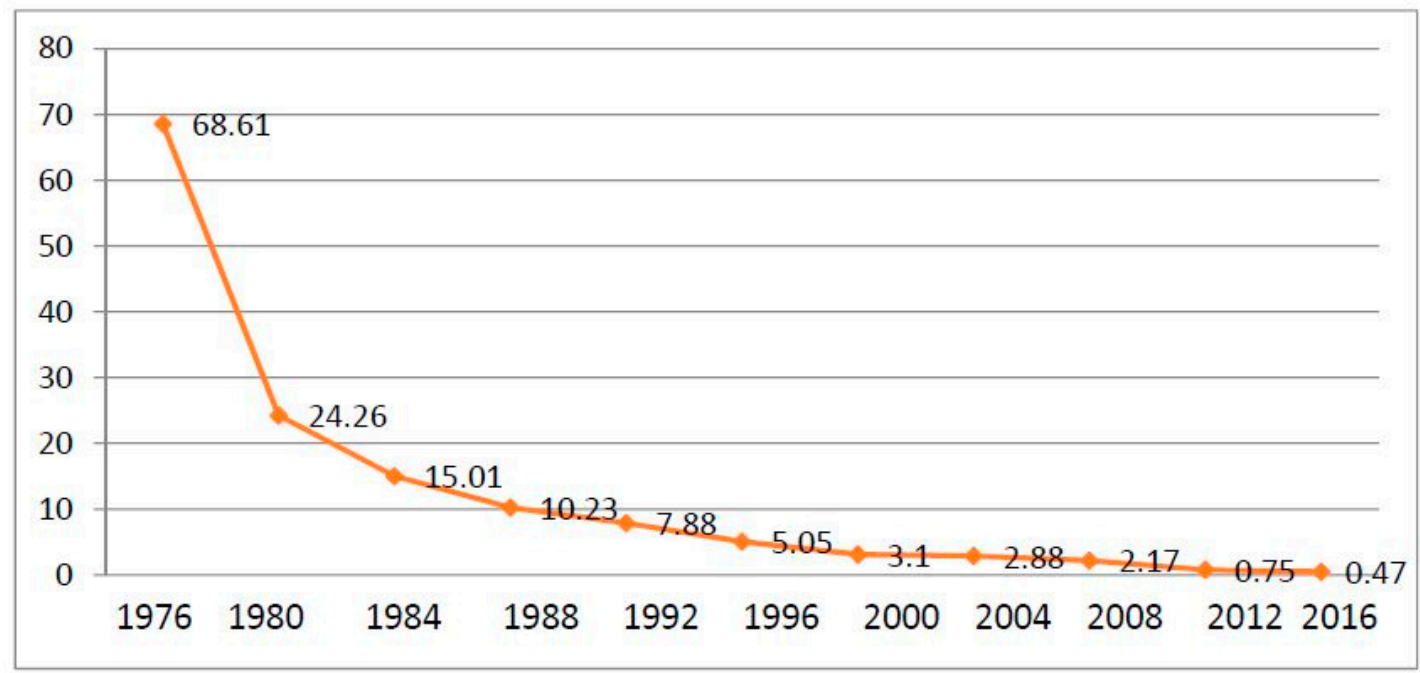

Figure 4. Global solar panel cost trend 1976-2016. Source: Mints, P. “Solar PV profit's last stand." Renewable Energy World 20 (2013) [7].

From these figures, we can conclude that investments in green technology for the abatement of GHG emissions become much more feasible over time. Unfortunately, we do not have enough time and resources to apply all of these technologies in our daily lives. Therefore, the role of the government becomes far more important for the development of these green technologies. Government policy has two directions, those of promotion and regulation. For free or low-cost technical measures, regulatory policies allow a much faster adaptation of the appropriate technologies, while high-cost technical measures may not benefit from severe regulation, but rather strong promotion through subsidies or tax incentives for the company to invest more in these green technologies. Depending on the cost-effectiveness of green technology development, the role of the government should be flexible, using regulation for low-cost or free technical measures, or promotion for high-cost technical measures. Of course, it is not always easy to determine whether policies should be regulationor promotion-oriented. Inappropriate policy directions can sometimes aggravate environmental problems [9]. The most representative policy failure can be found in diesel car promotion policies in Korea in the 2000s. The Korean government promoted the choice of diesel cars in the private sector with a range of incentives, including exemption from environmental taxes, because diesel cars produce very low rates of $\mathrm{CO}_{2}$. Due to this incorrect use of incentives as a signal, foreign car manufacturers enjoyed rapidly increasing exports to Korea and the market share of diesel cars increased by more than $40 \%$ [10]. In 2015, the Korean government found that PM 2.5 smog comes mainly from diesel cars, because while these cars produce low $\mathrm{CO}_{2}$, they have very high $\mathrm{NO}_{\mathrm{x}}$ emissions, which are a major cause of air pollution. Therefore, the government suddenly changed its policy from pro-diesel cars to anti-diesel cars. Soon, the government found that most microbusinesses used diesel cars in their operations and could not change these vehicles in the short run, resulting in further incentives. The government changed to using heavy environmental taxes. There have been confusing policy shifts between these two extremes of regulation and promotion. In the process, the Korean car manufacturing industry lost a golden opportunity to stimulate green technology development in electric and/or hydro cars. Due to this lack of consistent policies, Korean car manufacturing industries lost their future competitiveness [10]. The reason for such policy failures comes from the fact that the policy-makers believe they are smart enough to lead the market, but do not understand that no policies can win against the market. The sustainable governance of environmental policy should come from the harmonized efforts of both public and private sectors.

Unfortunately, most papers on environmental issues conclude that regulatory policies will enhance environment-friendly efficiency, known as the Porter hypothesis $[9,11,12]$. This may be true in the 
initial stages of green technology development, especially in developing countries such as China, but one-directional regulation may result in a range of harmful outputs, with the Kyoto Protocol providing us with an example of a top-down approach with partial success, despite resistance from the private sector. The Chinese government promoted the solar energy industry with heavy incentives, but this just resulted in an oversupply of solar panels and crowding-out effects on major leading solar companies around the world. Certainly, government-led transitions toward green growth are never easy or effective approaches without the strong participation of the market. A government-led economy as a leading environmental trendsetter, therefore, is not feasible. This implies that although most papers emphasize the regulatory role of the government, a government-led transition is really "mission impossible". There were too many demonstrations against wind power facilities in Korea, for example. Most Korean people say "it is good, but not in my backyard (NIMBY)", because it does not give any direct benefits, but only poses sacrifices for the public, such as loud noise, decreasing land or housing prices, etc.

On the other hand, subsidies for solar energy provided "blind, easy money" for solar technology developers and implementation companies. Meanwhile, most Korean households do not want such subsidies on solar energy, because it does not guarantee sustainable performance. If any new problems arise, nobody supports the maintenance of these solar facilities. The technology developers and/or installing companies obtain the subsidy funds regardless. This kind of "consultocracy" is a critical barrier in government-led economies such as China and Korea [13] (p. 38). Here, consultocracy means that intermediary consultants argue over and confirm the feasibility of new systems, methods, and strategies for the market, without sufficient consideration of market factors, which include economic efficiency, company capacities, and technical interfaces with the legacy system. Therefore, to reach the goal of the Paris Agreement, the participation of the general public is also necessary. Without behavioral changes in the public sector, the mission of the Paris Agreement cannot be achieved, because the participation of the public constitutes up to $8.5 \%$ of GHG reduction targets [14].

Based on all of these arguments, we should develop harmonized public-private partnerships (PPPs) based on Asian values of trust and loyalty to act as the trendsetter toward green growth. Why are these Asian values of trust and loyalty so important to sustainable PPPs? In order to answer this question, the conceptual characteristics of Asian values as guānxì will be examined more in detail.

\subsection{Conceptual Characteristics of Guānxì}

The environmental challenges under the Paris Agreement are really akin to mission impossible, due to the ambitious GHG reduction targets and the related risks arising from the unavoidably complex processes of sustainable development. In order to find the optimal control path toward this new 2020 climate regime, the most important governance focus should be on these public-private partnerships, because neither regulatory nor promotional environmental policies are effective unless all stakeholders voluntarily cooperate together to create value through sustainable performance. Since this new direction of sustainable development has not yet experienced a successful model for the global economy, Asian countries could become the new trendsetters toward green growth. Asian countries have strong common cultural virtues with respect to the community to which they belong. Instead of "I" or "myself", Asian people prefer to use "we" or "ourselves". This kind of "we can do it" spirit is very important for the successful governance of PPPs, and thus the cultural virtues of this kind of inspirational network could form the great cornerstone of Asian values.

The traditional paradigm of economics is based on economy or efficiency within the perspective of "I or myself". Contrary to Western countries, as the terminology jingjixue or jingshijiminxue implies, the economics in Asian countries is based on the philosophy of "with people, manage the world", meaning the sharing of future challenges among "ourselves". In Asian countries, we find a totally different approach to economic issues: not to seek the competitive solution, but the harmonizing solution for all! This is one of the most common cultural factors in Asian countries. They expect professional economic leaders and their policies to be based on value creation for "our groups"; value 
sharing beginning from the individual, via family, local community, and government, up to the group as part of global society or humankind. In this social order, the most important virtue is the trust given to the leader and loyalty among the followers. It implies that, if the Chinese government sets up a new "Chinese Dream (Zhong guo meng)" then the people feel they have to show loyalty in following the indicated direction. This implies that China is based on a government-led economy.

In Japan, harmony is the most important cultural value, because meiwaku (being out of group harmony, or becoming a loose cannon) is harmful behavior for all and thus these kinds of selfish activities are forbidden. From elementary school, all Japanese people learn that they should not break the social invisible order, or behave against other people's interests. In this kind of group or community-oriented society, individuals should not raise different opinions against the group or group leader. "Loyalty" to each person's wider society is crucial for social relations. Compared with Chinese or Korean people, Japanese go one step further in this loyalty, because they believe in sontaku, implying that even if the other party does not give any specific order or direct command, they should know what they need to do for the other party from the surrounding conditions and historical context. This kind of strong interrelationship creates invisible values of sharing responsibility, as well as establishing the rights of the group. This kind of oyabun-kobun (leader-follower) relationship is very important in meeting predictable future challenges. Even if the government or company leader sets impossible future goals, the people following them do not complain against this direction and do their best to promote the policy or business strategy with all their efforts. Therefore, Japan can be clearly categorized as a government-led economy, due to this cultural background.

Despite the many demonstrations on the street against government policies, Korean people also have strong cultural values of loyalty for "our community or our group", and this kind of "we-spirit" is crucial for Korean people to engage in group-oriented activities. When the IMF (International Monetary Fund) foreign currency crisis struck in 1998, the Korean people all sold their gold rings, gold medals, and gold-made precious items in return for US dollars, and this formed a great stepping stone for the Korean economy to undergo all the painful restructuring required to achieve an advanced economic structure. In 2002, the Korean people spoke with one voice of applause for the World Cup football tournament in Korea and the global population witnessed this fever of "we are the one!" enthusiasm in the streets, in schools, in businesses, everywhere.

Compared with the Western countries of the United States and the European Union, which have adopted market-oriented, promotion-based environmental policies, the northeast Asian countries follow strongly government-led, regulation-based policies, as shown in Figure 5.

Figure 5 indicates that the northeast Asian countries are based on strongly government-led top-down environmental policies. As discussed above, however, such government-led policies may result in a consultocracy, with resulting policy failures, due to a lack of adequate business knowledge and market-oriented experience. Without the strong support of the private sector, it is almost impossible for governments to promote sustainable development. In 2018, for example, the Korean government faced unworkable recycling challenges with vinyl plastic materials. The Korean government implemented a volume-rate disposal system from the year 1995 that requires residents to purchase and use special trash bags [1]. All trash has to be disposed of in state-authorized plastic bags that were made available at local stores. However, the recycling of materials such as bottles, cans, and vinyl plastic bags is exceptional. These materials were free in terms of the consumers, because the producer's liability (PL) law will pay a priori for these materials for recycling. However, due to the massive effort required for these recycling processes, the recycling companies claimed that they could no longer collect and process vinyl plastic, because most of the vinyl was too dirty and too sticky to clean and recycle, so the costs were ever-increasing. There are many reasons for this lack of governance with regard to vinyl recycling. One of the most important reasons arises from the consumers' negligence in undertaking vinyl plastic waste disposal. Using the same system, Japanese people are very considerate in disposing of vinyl plastic bags. They clean most of the vinyl before they throw it out, making it easier for the recycling companies to decrease the effort required to handle the recycling process. The difference between Korea 
and Japan lies in the behavioral effectiveness of the population. Japan does not have any problem with the proactive participation of consumers, while Korean consumers think it is "none of my business", and because it is free, they do not care about the disposal process. Therefore, the interrelationship between public and private sectors is very important to achieve better performance in environmental policies. This is the background of the Asian approach to these kinds of undesirable outcomes of environmental policies, in terms of Asian PPP models with the governance factor of loyalty as an Asian value.

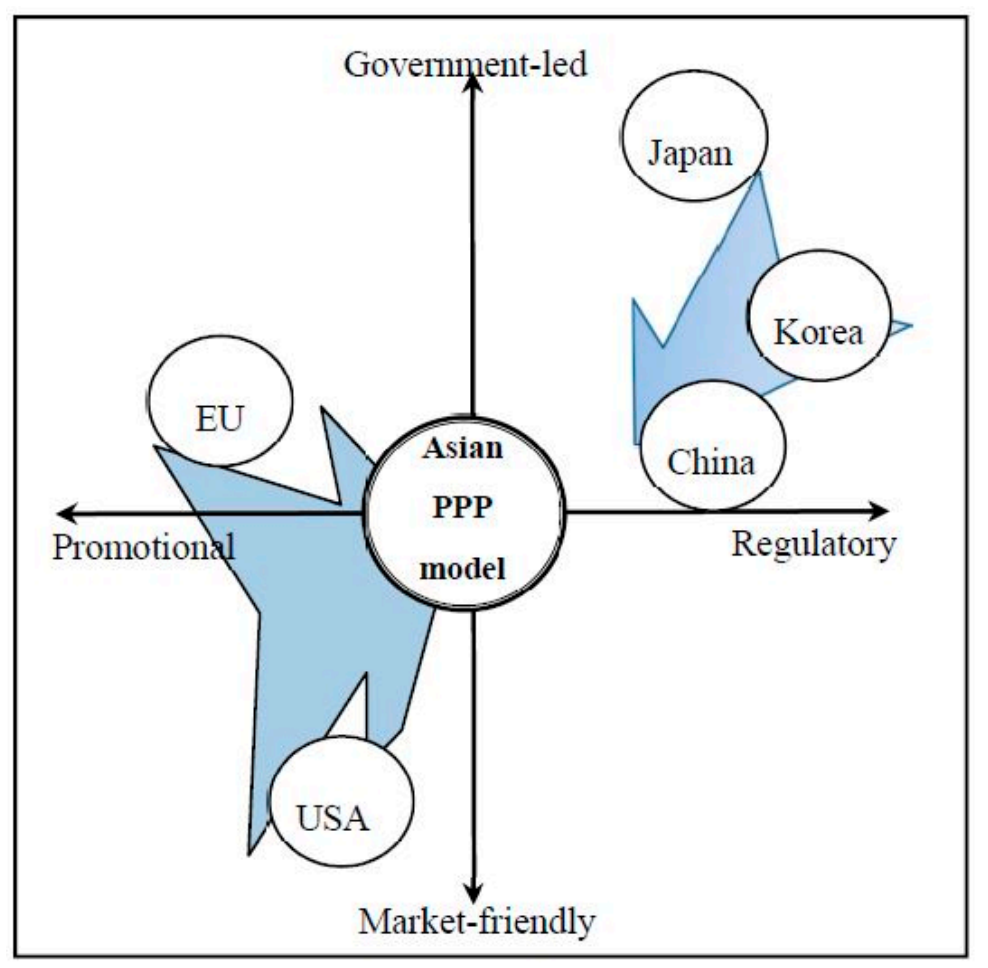

Figure 5. Green growth policy paradigms of various nations. Source: Modified by the author based on Choi [15] (p. 14,794).

In terms of Asian values, the most important governance factors should be based on interrelationships. To promote mutual benefits, the traditional paradigm underlying the feasibility of policies or business strategies in Western society is based on "trust," while in China, guānxì is the most important factor for new business, new projects, new policies, etc. [16] (p. 412). Guānxì is the most important value for interrelationships in northeast Asian countries, because it provides a strong stepping stone to enter the cooperative network easily and effectively. However, for most people in Asia, and even in China, guānxì is misunderstood. In general, it is interchangeably used with "connections" or "relationships", while neither of those terms sufficiently reflects the wide cultural implications that guānxì describes in China or Asian countries under the cultural background of Confucianism [17].

In Asia, guānxì is key for the feasibility of new policies, businesses, and any type of new project. Guānxì is different from simple trust, in that the latter emphasizes horizontal, bidirectional belief, while the former focuses on diverse, stepwise, mutually beneficial interdependence. Guānxì also acts as an essential informal governance mechanism, helping leverage Chinese organizations on social and economic platforms [18]. When business interactions are less efficient to facilitate, guānxì can serve as a way for businesses to circumvent such institutions by having their members cultivate their interpersonal ties [19]. Of course, sometimes the guānxì network may also violate bureaucratic norms, leading to corporate corruption [20]. Therefore, sustainable governance in guānxì is so important. 
The ideal of guānxì can best be found in the inaugural meeting of three historical heroes in China (táoyuán jiéyì). Even though they all came from different families, they made a brotherhood commitment to share their futures. As shown in this famous case, guānxì is not just human relationships or social networks to share trust within China or other Asian countries, but the basic "social platform" for the economic system, as well as the core of business activities. One famous Chinese researcher, Fei Xiaotong, defined guānxì as a "tidal wave" style of social relationship, as shown in Figure 6 [21]. To illustrate, all of the social activities surrounding myself can be supported by orderly stepwise guānxi (chaxù géjú): from the lowest level of friendship with my neighboring people, which gives simple acquaintance as a social contact point, via relative-oriented guannxì with the fellowship of mutual trust, to the highest level of family membership with full loyalty. The lowest value of guānxì is based on the easy and effective ability to communicate with each other, at least in the initial stage of cooperative projects, while the highest value is loyalty, which is the cardinal Asian value in PPPs.

People use one of these or combined guānxì qualities in relation to other parties. If all of the other parties are in the category of the highest level of loyalty-based guānxì, then one should not have any difficulty in achieving cooperation, while with the lowest level of friendship-based guānxì, you may have a limited degree of easy access to a new project but cannot expect more difficult or uncomfortable decisions from the other parties. Sometimes, this kind of spiral guānxì can be defined as initial trust and ongoing trust; and ongoing trust can be interpreted as sustainable loyalty [22]. Therefore, guānxi is the core of sustainable governance for collaborative new projects. If you know your partner in depth through the recommendation of your intimate friend or family member, you will devote more effort to cooperate with this new partner, even in unknown projects. Fei Shaotong and Choi clearly defined guānxì as comprising diverse levels of value-sharing in social networking, and thus effective network management could be crucial for the successful and sustainable performance of green growth policies. Therefore, governments or local communities in Asian countries should encourage the private sector to enhance its guānxì toward all relevant interest groups. The aim of people in the guānxì network is not that of maximizing profits or efficiency, but rather acting as partners to create value based on voluntary innovation to enhance their positions in this radiating wave type of guānxì.

The most important character of guānxì comes from value sharing. It is a mutually beneficial relationship with the slogan, "If you make me a hero, I will make you a hero"; in this respect, it is very similar to the "give and take" spirit of Western society. However, guānxì is much more diverse in its contents and deeper in the responsibilities of the relationship. The second characteristic of guānxì is more functionally oriented in its effect on social activities. It does not clearly show the level of loyalty in a given social relationship and it does not guarantee any responsibility arising from a guānxì-based recommendation. Nonetheless, guānxì excludes any free rider problems, because if you fail to meet expectations, all the related parties may have damage to their guānxì, resulting in mutually worsening outcomes, which makes the parties to the guannxì relationship work better. The third characteristic of guānxì is based on the indirect nudge effect, implying the use of positive reinforcement and indirect suggestions as ways to influence the behavior and decision-making of groups or individuals in new projects. Even if there is no clear or direct content conveyed by guānxi, it provides diverse areas for the related parties to consider. In Asia, without any specific written relationship, guānxì may sometimes create even stronger effects in very flexible ways. Finally, guānxì is based on the membership of one's own community or group, and thus the success of the community or group should take precedence over individual success. Individuals are ready to enhance guānxì by serving its leadership with more contributions, or sometimes making sacrifices for "our group or our community" as a larger family. In the famous story of three heroes in the three-country Chinese legend, Zhu Geliang died for Liu Bei and his son because of his strong brotherhood type of guānxì. This ideal type of guānxì is very influential for all Chinese people in their social activities.

Unfortunately, guānxì is not easy to create, maintain, and utilize as social relationships for sustainable performance. However, if we have strong guānxì for a new project, it is much safer and easier for the parties to perform in more effective ways. One of the most important tasks is establishing 
how to create and manage guānxì, especially for the risky and uncomfortable future challenges of sustainable development in stepwise progression starting from acquaintance, via initial trust, until the in-depth loyalty of Asian values has been achieved, as shown in Figures 6 and 7. In order to find the optimal path toward the Asian PPP model as a collaborative network, the following Section will propose strategies for network management, transforming the government-led economies to move along this optimal path of governance.

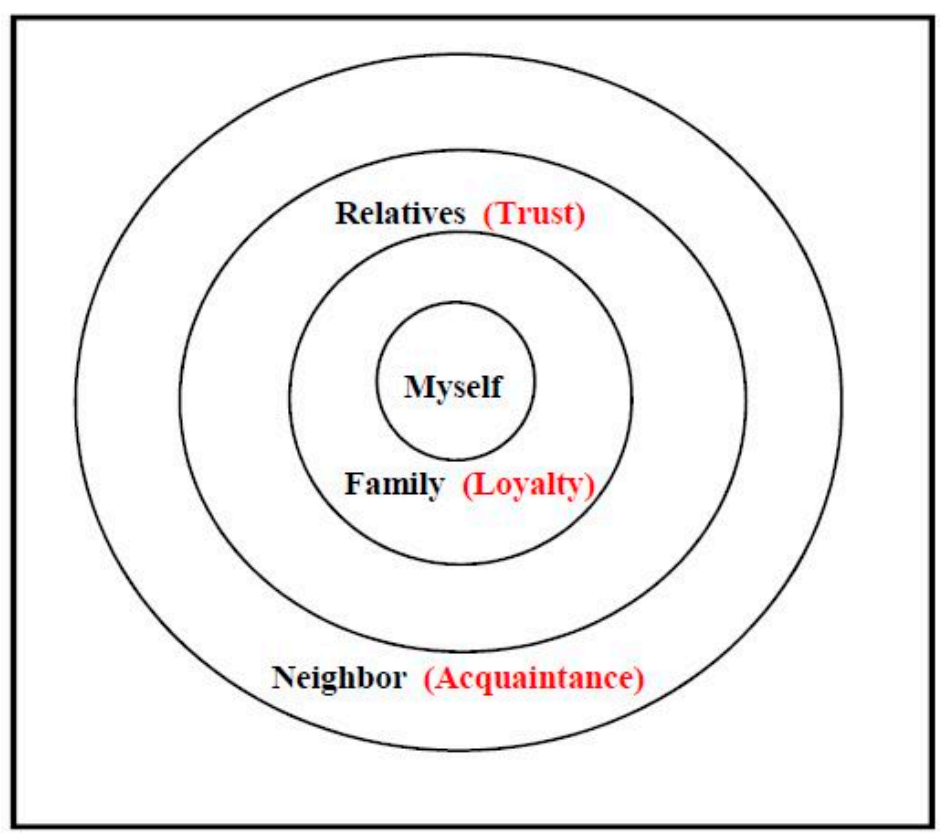

Figure 6. Guānxì as an intimacy wave of social relations (chaxù géjú) [23].

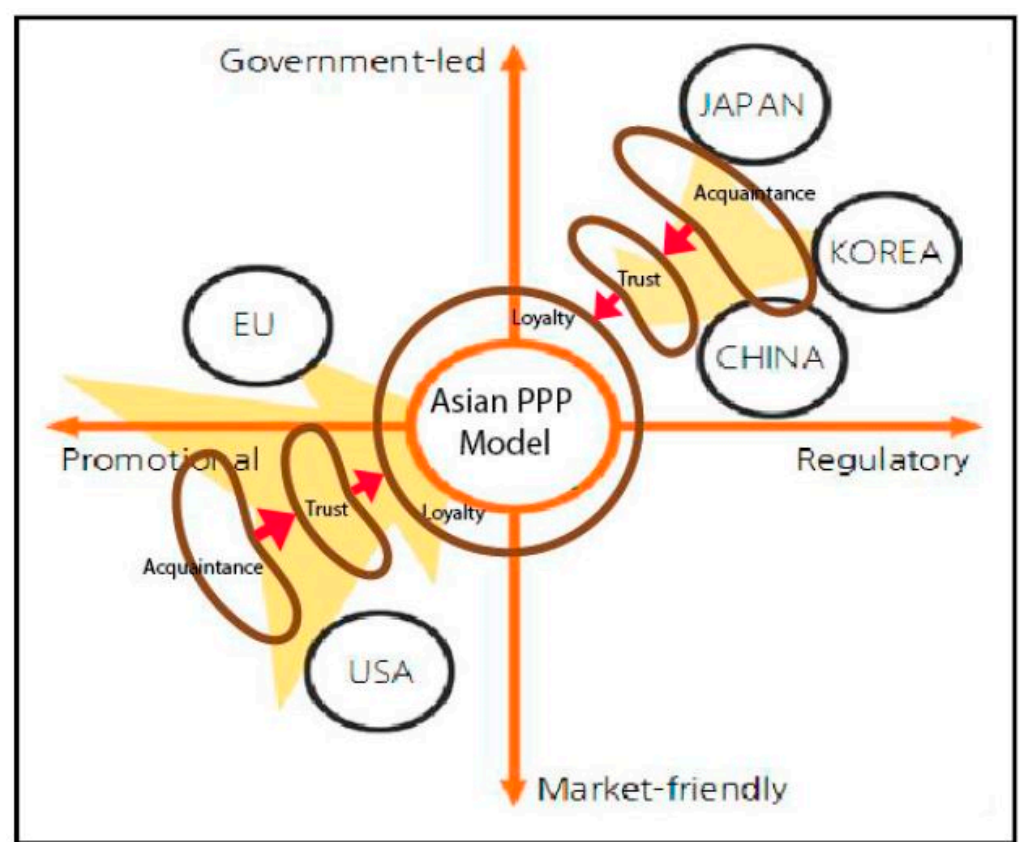

Figure 7. Stepwise guānxì approach toward the Asian public-private partnership (PPP) model. 


\section{Propositions on the Asian Model: Sustainable PPP}

\subsection{Structural Factors of Asian PPP}

Public-private partnerships (PPPs) are defined as long-term, cooperative relationships established between the public and private sectors [24]. In general, PPPs have been widely applied in infrastructure development of the build-operate-transfer (BOT) model. However, PPPs represent a very diverse type of spectrum in the cooperative networks between the public and private sectors, from the simple project type to the joint venture type of permanent organization. In the field of environmental issues, one can consider diverse yet flexible types of PPPs. It is not meaningful to consider a specific type of PPP, because the most important content is not in the organizational structure, but in the governance factors adopted to manage a sustainable transition to the path of optimal green growth. Therefore, all the social science paradigms in the literature will be examined to describe these diverse governance factors in more detail in the following sections.

As strategic alliances across government, industry, and the public, PPPs should be examined in terms of organizational governance factors. Structural or organizational styles and types of PPPs could vary from pure stakeholder relationships to unified joint venture types of public companies. For example, when a new Korean president initiates a new administration, POSCO, a representative steel manufacturing company in Korea, tends to change its presidency as well, because of invisible pressure from the new government. Even though this is a purely private company with no stock held by the government, due to its symbolic position in the Korean economy, the old president will resign and let the government appoint a new person in his position. Otherwise, there may be multiple trouble-shooting investigations undertaken by the government and the invisible pressure becomes a major risk for the future of the company. This kind of unfortunate repositioning happens with almost all utility companies, such as KT, KEPCO, etc. Many public research centers and institutions also change their leaders according to the new government. Thus, predictable, transparent policies are not feasible in many areas, especially within sustainable development.

President Lee reached a significant milestone for sustainable development with his very ambitious mission for the year 2020; but soon, his successor President Park changed the mission to a greatly loosened version, aiming not for 2020, but 2030. Now President Moon, following President Park, has changed again, with more flexible but confusing targets for the year 2030. In the process, the new president made a commitment toward zero nuclear power in Korea, and tried to stop all new construction and development of nuclear power plants. However, he faced too much opposition against these new policies, because some nuclear power plants had already spent millions of dollars, and moreover, Korea had already exported its first Korean style of nuclear power plant to the Middle East. Finally, the new president organized a single screening committee to decide whether to complete the construction of nuclear power plants or not. Without any professional experts among its members, the committee decided that all nuclear power plants in the construction process should complete their missions, due to the huge costs already sunk into these projects. While this was being decided, there was another huge monetary loss due to the standstill of the construction process. This kind of invisible interruption from the government side is outside of the legal structures of PPPs such as Korean Electric Power Company (KEPCO); but it frequently occurs in China, Korea, and Japan. Due to these interruptions from Big Brother, PPPs cannot gain optimal control over their own future challenges. This is a real problem in government-led economies. Due to this kind of top-down approach, strong structural governance factors are definitely necessary.

Government-led economies could be very efficient, at least in the initial stage, in strong and reliable promotion for early adapters. Moreover, in the relatively short history of industrialization in Asian countries, government leadership has produced tremendous performances against the historical and cultural background of guānxì, resulting in proactive participation by local companies and the people. However, as shown in the Kyoto Protocol, government leadership that goes against the market cannot continue in the long run. In particular, sustainable development is too complex for the government 
to take the one-way-driven, top-down approach. In Korea, there have been too many trial-and-error exercises by the government in air pollution management. Most major countries, facing severe challenges in GHG emissions, have adopted the structural approach to monitor the production process precisely and manage air quality. In January 2018, the Korean government proclaimed an air quality emergency due to PM 2.5 smog. All schools closed for two days and public transportation in Seoul was free, with people told not to use their cars. The government asked companies to allow only even (or odd) number-plate cars on given days during this emergency. However, all of these policy measures were not successful, because not many people participated in the public transportation campaign. While the government had only emphasized $\mathrm{CO}_{2}$ emissions, these are just a part of air pollution, as shown in Figure 8. Therefore, due to the ballooning effect of the consultocracy, this government intervention wasted a great deal of money without improving air quality in Seoul at all. The policy just facilitated the change from gasoline cars to diesel cars, from $\mathrm{CO}_{2}$ to $\mathrm{NO}_{2}$. As we can see in this case of policy failure, the government cannot and must not control all of the future challenges by itself, because the emphasis on one specific regulation may crowd out another potential opportunity, as shown in Figure 8. In this example, the government wanted to reduce $\mathrm{CO}_{2}$ emissions through subsidies, but this just resulted in excess $\mathrm{NO}_{2}$ due to the policy on diesel cars. Why does this kind of policy failure happen? Simply because the government did not try to listen to the voice of the market. In addition, the public was also excluded from the decision-making process, making the policy "none of my business." If the government had informed the public and found some indirect way to gather opinions from the market, then certainly this kind of policy failure could be avoided. The important mission to gain voluntary participation from private sector companies and the population, therefore, should first be based on the acquaintance between the public and private sectors, building trust based on information sharing, and finally attaining loyalty through voluntary participation in PPP networks.

In order to enhance these structural governance factors, therefore, these PPPs should have the following factors in their governance.

First, as a pure stakeholder without any contribution toward finance, the role of the government should be that of providing a "nudge strategy" only (principle of the nudging partner). Changes of leadership in private companies or any public organizations will destroy trust in governmental policies and the actors will remain at the acquaintance stage. Even if the government holds an equity share, it should remain as one of the partners, because the partnership is key to the PPP process and too much government intervention may result in balloon effects elsewhere.

Second, the articulation of government decisions should be based on a harmonized approach with other partners (principle of the harmonizing partner). When the policy involves the other parties' interests and stakes, then it is certainly better that the government should realize all of the related parties' interests in a harmonized way, resulting in the voluntary participation of these groups.

Third, if the government has a big voice within PPPs, certainly it should have full responsibility for their decisions (principle of the responsible partner). In many cases, policy failures may result in lost or wasted resources without any government official or ministry taking responsibility. In these cases, private partners will tend to read government statements at face value, resulting in superficial show-off efforts only.

Fourth, the government should share values with its partners (principle of the sustainable partner). This is very important for the sustainable performance of PPPs. In most cases, the BOT type of PPP gives a lump sum of money to the participating private company from the government, and thus it may not perform sustainably, due the lack of incentives in the long term. As shown with the solar panel subsidy policy in Korea, households may have problems after the installation of these panels, and if they make claims against this, the subsidy recipient does not provide any after-service, because they received all the money as a lump sum from the government and thus there is no need for this company to undertake follow-up services. There are many research projects in Asia, especially in the field of environmental protection; however, most of the results from these government-supported research projects do not contribute toward any practical implementation and are thus just used as 
"decorative books" on the shelves. The government should reinforce its financial and/or political support for private partners based on their performance in a stepwise approach over time, resulting in sustainable governance through the beneficial circle of innovative, proactive participation of the private partners.

Fifth, as Big Brother, the government should let other partners cooperate with other collaborative networks as well (principle of the value-sharing partner). For example, if a local government creates a consortium with construction companies for a new green town development, the government should encourage the private partner to maintain further cooperative networks with second or third outsourcing construction-related companies as well. Even if the private partner along with the government do their best in performance, if this company does not cooperate with its own outsourcing companies for profit maximization, then the value chain with the local government cannot be managed in a harmonized, performance-oriented way. As the Paris Agreement stresses, not only the performance, but also the process behind the performance is important, and the government should monitor all of these value chains with private partners in structural ways to cooperate not only in profit-maximizing ways, but also in harmonizing ways for sustainable performance.

In CES (Consumer Electronics Show) 2017 in Las Vegas, USA, IBM declared its new slogan, not "Made in China", but "Made with China". This implies a paradigm shift for IBM from seeing China as a "global factory" to being a "global partner". China is no long just a passive assembler of parts and modules in the global supply chain management. IBM declared that they want to create a new future together with China. The slogan of Walmart, "The customer is always right", is also based on lessons that come from a legendary Chinese salesman. This paradigm shift implies that there should be no helpers to maximize my own company profits. Instead, all the partners surrounding my company make "us" to create values altogether to share our value in better, harmonized ways. That is the core of the structural governance factors of PPP. Mr. Jin Liqun, the president of the Asian Infrastructure Investment Bank (AIIB) said in his inauguration address, "We Asians will help each other as partners for Compliance, Effectiveness, and Integrity. The future of Asia is 'Ours' in 2016" [20]. This focus will create the best partnerships in PPP structures in the region.

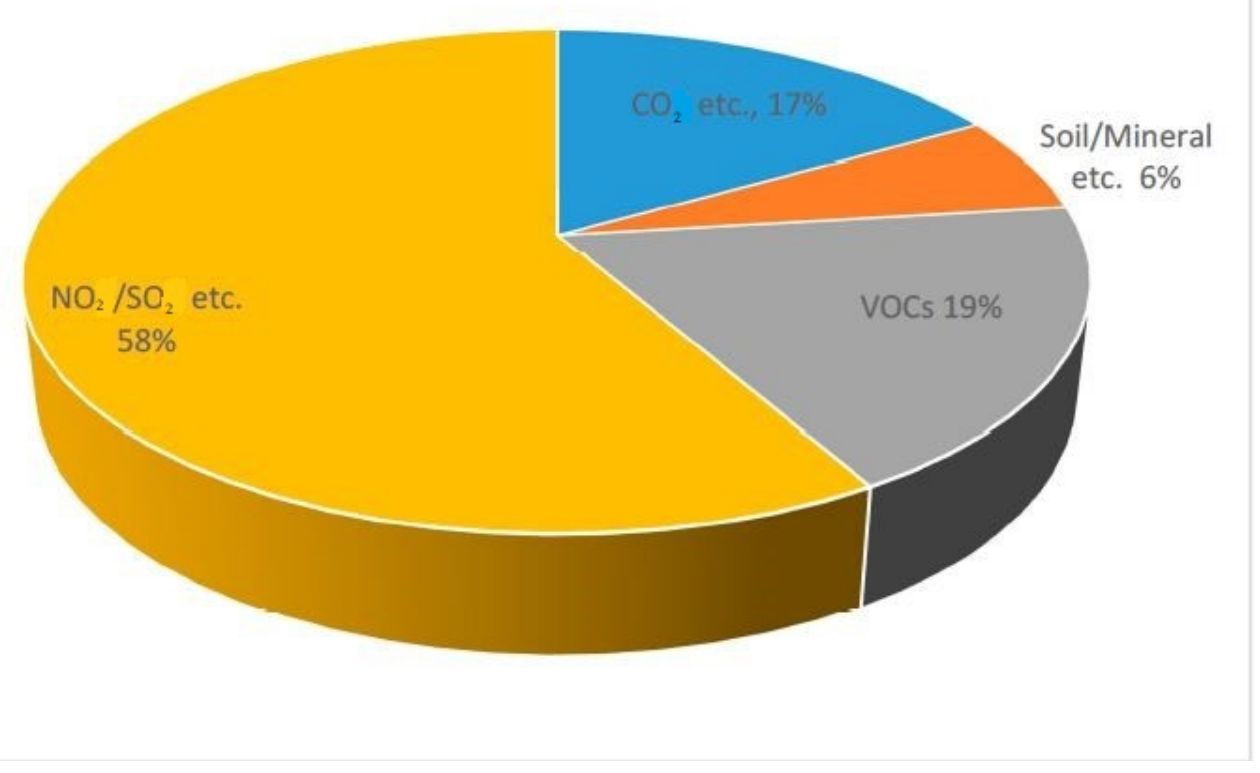

Figure 8. Particulate matter (PM) ingredients. Source: Air Quality with PM [25]. 


\subsection{Functional Factors of Asian PPP}

Six years after the Fukushima accident, when 67 residents came back to the destroyed city of Fukushima, they first organized a private solar company as energy farmers. This company is an example of PPPs in Japan between the local government and the general public. The citizens organized the PPP and local government provided support, including financial incentives and land use for the solar company. Local people got jobs with this PPP company, and due to its lower prices compared with the monopolized national electric company, most local businesses and households use this PPP as their electric energy source. Because of these mutual benefits with new jobs, the PPP is welcomed by all the stakeholders, government, consumers and workers, who are consumers as well and thus make greater efforts to enhance productivity voluntarily. To support this PPP, Fukushima airport, as one the partners, set up a global solar panel comparative research station in its open spaces, which continuously supports the innovative investments in green technology of the PPP. The energy farmers of this PPP dream of 100\% self-sufficiency with their solar energy by 2040.

In Sacramento, CA, USA, Rancho Seco nuclear power plant began its electric supply service in 1975, but due to the Chernobyl nuclear accident, it stopped power production in 1989. However, the citizens of Sacramento did not demolish this nuclear power plant. Instead, they set up new solar power facilities just next to it, through a new PPP with the Sacramento Municipal Utility District, as shown in Figure 9. This is now a symbol of harmonized cooperation between the local government and local people for the transformation of nuclear energy to solar. It supplies $10 \%$ of California's energy share at present, but the PPP plans to increase this to $33 \%$ by 2020 . The local people are proud of this transformation and thus they make efforts not to waste any electricity.

Germany also utilized environmentally friendly PPPs through two policies: all of the solar energy supplied shall be purchased at any time; and a minimum price is guaranteed. Because of these transparent and accountable policies, many small and medium renewable energy PPPs show good governance with sustainable performance. The reason for this successful governance clearly comes from the proactive partnership of the government with the private sector. They share the relevant business functions, such as marketing and financing, in more flexible ways. This is crucial for PPPs to achieve sustainable governance.

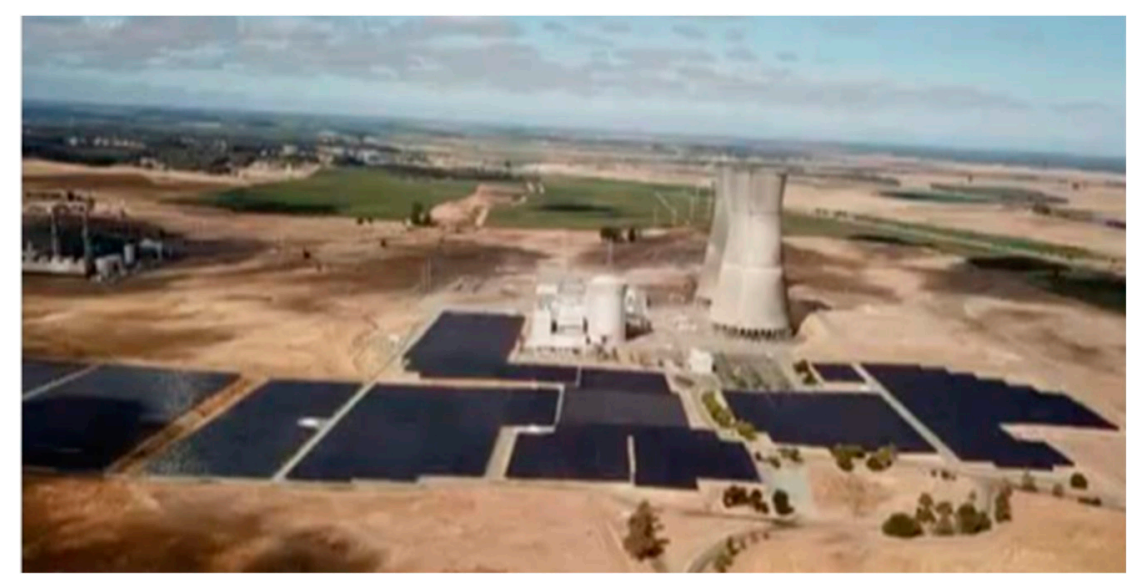

Figure 9. Rancho Seco nuclear power plant and its replacement with solar power.

Compared with these cases, some PPPs are not sustainable due to a lack of governance. For example, San Francisco implemented new regulations that all new buildings after 2016 should construct at least $15 \%$ of their roofs with solar panels. This does not seem feasible, because this kind of top-down approach through regulation can result in show-off effects only. The new buildings and houses have at least $15 \%$ of their roofs covered with solar panels, but sooner or later when there are any problems with these solar panels, many homeowners may not receive good after-service due to a lack 
of funds and information, resulting in idle solar panels and no sustainable performance. This could certainly be seen as a case of bad governance, because the government does not provide sustainable functional support and there is no motivation for homeowners to see themselves as better off by virtue of these solar panels.

Therefore, successful PPPs should have workable arrangements in the long term among all partners. For this purpose, all participants should share the values embedded in the partnership. Unfortunately, most government officials do not have this kind of sharing attitude and thus do not want to take responsibility. To make matters worse, due to the myth among elite government officials that the government is always right in Asia, there are too many conflicts, especially over environmental issues. In the period of 2012-2017, the Korean government spent 52.8 million dollars on air quality modeling, but only 5.1 million dollars for monitoring. Less than $10 \%$ of research funds went toward establishing the basic reasons behind GHG production, while more than $90 \%$ went toward the theoretical study of air quality modeling. It seems that the government promotes the development of artificial intelligence (AI) without an in-depth analysis of big data. This kind of nonsensical decision arises from the consultocracy of government officials. They should remember that they are not experts or professionals in all economic activities. In particular, when they initiate new PPPs over environmental issues, they should understand that they certainly cannot provide a panacea for all, and thus should let the private partners develop their business functions more effectively and efficiently. They should not use the consultocracy as a blind source of money that leads to show-off effects only. In order to avoid the consultocracy and develop sustainable governance factors in functional forms, the following propositions for intermediation by the government should be kept in mind for all partners. Choi (2009) described this kind of proactive network manager as a meta-mediary, implying that the role of the network manager should be that of a multitasking (meta-), proactive intermediary (mediary) [26] (p. 277). The three functional propositions are those of facilitator, collaborator, and one-stop service provider.

First, the government should create new businesses, new markets, and new users, as well as act as facilitator for all new participants in these innovative environmental policies. Since there is insufficient supply and demand in the field of meeting environmental challenges, few agents wish to follow this new trend, due to the formidable costs and diverse risks. All of these policy changes could be considered as having a bright side of opportunity, as well as a dark side of threats to the traditional legacy system; and thus it is not easy for companies to invest in green technology, or for consumers to participate in green consumption via habitual change with voluntary recycling, reusing, and reducing. If regulation or promotion are not appropriately organized, moral hazard sometimes arises in business with blind money and/or in government through the consultocracy. To avoid these two extremes, the new market mechanisms of facilitating innovative green investments, green technology, and green projects should get rid of any psychological as well as practical barriers, resulting in the good acquaintanceship of the parties through PPPs.

Second, the government should manage all of the participants in cooperation with each other as a collaborator. The government should not remain merely a helper, but should participate in the implementation of policies as a partner. The government should easily and effectively receive feedback from the other participants and modify its policies to be more performance-oriented. There are too many helpers and supporters in sustainable development at present. Committees, associations of companies, institutes, and other public centers could provide the necessary information; however, as helpers, they do not care about governance and thus many policies end up with show-off effects only. In order to avoid this kind of irresponsible support, the government should measure all of the participants' contributions in order to share the value from the cooperation appropriately. Of course, the government officials involved should gain some compensation from playing this role of network manager as well, resulting in improved trust.

Third, the government should provide all of the related information, as well as real, field-oriented services as a one-stop service provider. In most cases, the government is superior in terms of 
information and access to the appropriate sources. In contrast to government, business leaders and consumers are not efficient in collecting and utilizing information across economic and other relevant sources. Therefore, before the government asks for the appropriate application from a PPP consortium, it should provide all related services to the potential partners. Let these potential partners be ready to cooperate with the government at least in the field of sustainable development. The government may set up a third-party organization or even create simple websites for all interested groups to utilize this one-stop service, which is the ultimate goal of a smart e-government. If the government provides all of the policy measures required for a one-stop services, all partners will obtain emotional satisfaction, resulting in loyalty to PPP projects from all of the partners involved.

\subsection{Procedural Factors of Asian PPP}

Currently, China supplies one third of the world's solar panels. Among the top 10 largest solar panel manufacturers, seven are located in China, which is almost the same fraction as its 27 nuclear power plants. In its focus on the solar industry, China is certainly leading the world. Nonetheless, it produces $27 \mathrm{GW}$ per year, compared with $70 \mathrm{GW}$ in the world, which is much less efficient and has very weak governance. The reason for this may come from the oversupply policy failure in China's strategic industries. Even if the government promotes the issue very intensively, its private partners are not ready to participate in more proactive ways with green investments in the solar energy field. Due to this lack of governance in the private sector, the Chinese government made the global industry take a step backwards. Many leading global solar companies in Germany and the United Sates went bankrupt and disappeared, due to the excessively low prices of Chinese solar panels, subsidized by the Chinese government. The Chinese government wanted to lead the global economy through ambitious subsidies and other promotional incentives for the solar industry, resulting in an oversupply in the domestic market, as well as the elimination of potential challengers in the world, resulting in the eradication of any potential major efforts toward this innovation. The government should provide transparent, predictable future missions to its private partners, but in the meantime, the companies are just focusing on increasing their production capacity.

Another example can be found in the frontier of the floating solar system in Anhui province. Here, the local government built 160,000 floating solar power panels on a lake surface to produce $40 \mathrm{MW}$ for 15,000 households. It is the largest floating solar energy facility in the world. However, these solar panels are fixed on the water and are thus only workable for a few hours a day. Compared with this PPP supported by the Chinese government, Ansung city in Korea built 1750 rotating floating solar power panels for 250 households. Even if this is not particularly economical in terms of scale, as well as being in an undesirable environment, due to the lake just getting a few hours of sunshine daily and little direct sunshine at all, it has good governance as a procedural innovation. In order to solve the difficulties involved, the PPP created rotating, floating solar power generating panels on the lake with the innovative participation of the companies involved. When there is sunshine, the panels rotate by 4 degrees per hour to gain more direct sunshine. This is a much more innovative approach. The difference between these cases in China and Korea lies in the voluntary participation of the private sector with much stronger motivation in the innovation. How should we promote this kind of innovation by the partners in other PPP projects? In order to find the answers for these governance issues, the seven procedural governance factors outlined should be met precisely.

To promote PPPs more proactively in the implementation process with a stepwise approach to enhance guānxì, seven procedural propositions should be met. First, design a vision-based PPP implementation framework and a built-in monitoring system at both public and private levels; there is no winner in the world against the market, and thus Asian governments should listen to the voice of the private sector for a win-win type of vision or mission. Second, maintain a consistent strategic orientation among leaders; these leaders should show transparent, predictable optimal control paths towards green growth. Third, improve interdependence between public and private partners in the strategic sharing of business functions such as financing and resource sharing under 
fair competition, while preventing corruption [27]. Fourth, support institutional guarantees through a better composition of the professional workforce involved in the implementation, because the inauguration of the new PPP project may require the elimination of any psychological barriers through such guarantees. Fifth, consolidate management strategies with new technology through the training of various kinds and at different levels, because the portfolio for business success comes from the three factors of business strategy, unique technology, and financial resources-not independently, but in integrated ways. Sixth, the PPP procedures should be harmonized through the value-sharing system. If any partners in the collaborative network of a PPP contribute uniquely to value creation, then certainly there should be some compensation mechanism for the deepening and widening effect of these innovations. Seventh, there should be mutual beneficial circulation of new knowledge. The organizational culture that says, "if you make me a hero, I will make you a hero," will provide good governance feedback for sustainable performance. By so doing, some potential risks in terms of government debts, credit, quality supervision, and orderly management could be avoided in advance, and the private sector may not succumb to moral hazard with government subsidies.

\section{Conclusions}

In this study, we proposed the Asian value system of guānxì as a core factor for sustainable development, because it is a new paradigm, involving not just the maximization of a single economic agent's profits and/or efficiency, but embracing a harmonized way to create values based on collaborative networks. Collaborative networking of green growth policies is so important in the modern interdependent society that we should ensure that sustainable performance falls within this networking, especially in establishing the complex procedures of sustainable development or green growth. Nonetheless, sustainable development is not optional, but is the survival kit for humankind, and thus collaboration for sustainable development is essential for our future. Unfortunately, there have been too many policy failures, especially in the field of sustainable development, due to a lack of governance. Many private partners in sustainability projects essentially just cheat to get the "blind, easy money" of government subsidies; much of the public complains that they do not want to make any sacrifice on behalf of public welfare (NIMBY); and government officials lack governance skills due to the irresponsibility of their policies, resulting in the rise of the consultocracy.

In order to avoid all these moral hazards and a lack of governance in sustainable development, we proposed the Asian PPP model to create sustainable collaborative networks between the public and private sectors in terms of structural, functional, and procedural perspectives. The government should build these harmonized PPP networks based on the five structural principles of the nudging partner, harmonizing partner, responsible partner, sustainable partner, and value-sharing partner. As the third-party intermediary between the public and private sectors, specific PPPs with a sustainable development mission should have three roles of facilitator, collaborator, and one-stop service provider. Finally, these PPPs should have transparent, predictable optimal projection pathways with the seven procedural factors outlined.

All of these five structural, functional, and procedural principles, three propositions, and seven factors will result in a virtuous circular mechanism leading to good governance for all partners to create and share values based on their collaborative network. This is the ultimate mission towards achieving an Asian model based on the Asian value of guānxì.

As already explained, the traditional economic paradigm on the efficiency and/or business management paradigm on the profit maximization is no longer useful, at least in the fields of environment and energy. Because the latter emphasizes the long-term relational management to create "value", it is not easy to handle the new issues of sustainable management and sustainable development in harmonizing way among all of the interest stakeholders. That is the reason why this paper focuses on the qualitative approach to fill this missing links among the interest stake-holding groups, in terms of human relationships. 
The Asian value of loyalty, as the core of guānxì, comes from emotional sharing of values based on the partnership between public and private sectors: once a friend, forever a friend. Performance-oriented value-sharing mechanisms should be based on the flexible, predictable, transparent, open PPP of the Asian model, following the sentiment that "if you make me a hero, I will make you a hero". Unfortunately, there are too many passive helpers and too many aggressive critics. The government-led economies of Asian countries have the mission to discover good partners and ask for help. Even if these Asian values and Asian models are found to involve complex and tricky processes, if all of the partners, including the government sector, evaluate them appropriately and produce their best efforts, then certainly all Asian countries will successfully transform their economies toward becoming trendsetters at the frontier of green growth.

This paper tried to show the optimal path toward sustainable development in terms of stepwise approaches based on guānxì, the Asian value. Nonetheless, it is not clearly convincing in its methodologies, thus revealing a limit of this research. A future challenge will be to identify its explanatory power. In general, qualitative approaches, well-known and often used in other fields, have the basic assumptions and conditions of the approach explained, along with the common challenges of the approach. In this paper, instead, the cultural background of guānxì is introduced as an Asian value, and based on guānxì, the stepwise assumptions are developed from the acquaintance level via trust, and finally to loyalty. Since these conceptual characteristics of guānxì in the sustainable governance of environmental policies are not easily measurable and/or capable of having their performance monitored, much more precise articulation will be needed in the future challenges of the quantitative analysis of guānxì [28].

Acknowledgments: This paper was presented in the Sustainable Asia Conference (SAC) 2018 on 19 May 2018 at Beijing. The paper was awarded The Best Paper Award in the conference by the Chinese Academy of Science. The author appreciates all the participants of the SAC 2018 and anonymous referees for their valuable comments. This paper was supported by the Inha University.

Conflicts of Interest: The author declares no conflict of interest.

\section{References}

1. Choi, Y. Digital Business and Sustainable Development: Asian Perspectives; Rotledge Publishing Co.: London, UK, 2017.

2. Choi, Y. Editorial to the special issue "Sustainable energy policies in Northeast Asia". Energy Policy 2018, 112, 301-304. [CrossRef]

3. Lee, E.H. Proceedings of 2016 International Conference on Climate Finance and Industry; IGC Forum: Incheon, Korea, 2016.

4. Bloomberg New Energy Finance. State of Clean Energy Investment. Available online: https:/ /about.bnef. com/clean-energy-investment/ (accessed on 17 April 2018).

5. Bloomberg New Energy Finance. Global Trends in Renewable Energy Investment 2017. Available online: http: //fs-unep-centre.org/sites/default/files/publications/globaltrendsinrenewableenergyinvestment2017. pdf (accessed on 17 April 2018).

6. REN21. Renewables 2017 Global Status Report; REN21 Secretariat: Paris, France, 2017. Available online: http:// www.ren21.net/wp-content/uploads/2017/06/17-8399_GSR_2017_Full_Report_0621_Opt.pdf (accessed on 17 April 2018).

7. Mints, P. Solar PV Profit's Last Stand. Renewable Energy World 20. 2013. Available online: https://www. renewableenergyworld.com/articles/2013/03/solar-pv-profits-last-stand.html (accessed on 17 April 2018).

8. U.S. Energy Information Administration. Levelized Cost and Levelized Avoided Cost of New Generation Resources in the Annual Energy Outlook 2018. Available online: https:/ /www.eia.gov/ outlooks/aeo/pdf/ electricity_generation.pdf (accessed on 17 April 2018).

9. Zhang, N.; Choi, Y. A note on the evolution of directional distance function and its development in energy and environmental studies 1997-2013. Renew. Sustain. Energy Rev. 2014, 33, 50-59. [CrossRef]

10. Korea Joongang Daily (Newspaper). Is Plan to Ban Diesel Feasible? 2017. Available online: http:// koreajoongangdaily.joins.com/news/article/article.aspx?aid=3033562 (accessed on 17 April 2018). 
11. Oestreich, A.M.; Tsiakas, I. Carbon Emissions and Stock Returns: Evidence from the EU Emissions Trading Scheme. J. Bank. Financ. 2015, 58, 294-308. [CrossRef]

12. Wei, Y.-M.; Liao, H.; Fan, Y. An empirical analysis of energy efficiency in China's iron and steel sector. Energy 2007, 32, 2262-2270. [CrossRef]

13. Choi, Y. The role of intermediation on the international aid for the governance of technical training program. Technol. Forecast. Soc. Chang. 2015, 96, 32-39. [CrossRef]

14. McKinsey Co. Greenhouse Gas Abatement Cost Curves. Available online: https://www.mckinsey.com/ business-functions / sustainability-and-resource-productivity/our-insights / greenhouse-gas-abatementcost-curves (accessed on 17 April 2018).

15. Choi, Y. Intermediary Propositions for Green Growth with Sustainable Governance. Sustainability 2015, 7, 14785-14801. [CrossRef]

16. Yeung, H.W.-C. Handbook of Research on Asian Business; Edward Elgar Publishing: Cheltenham, UK, 2007; ISBN 978-1-84720-318-2.

17. Gold, T.; Guthrie, D.; Wank, D. Social Connections in China: Institutions, Culture and the Changing Nature of Guanxi; Cambridge University Press: Cambridge, UK, 2002.

18. Gu, F.F.; Hung, K.; Tse, D.K. When Does Guanxi Matter? Issues of Capitalization and Its Dark Sides. J. Mark. 2008, 72, 12-28. [CrossRef]

19. Hasmath, R.; Ho, B. Job acquisition, retention, and outcomes for ethnic minorities in urban China. Eurasian Geogr. Econ. 2015, 56, 29-30. [CrossRef]

20. Luo, Y. The changing Chinese culture and business behavior: The perspective of intertwinement between guanxi and corruption. Int. Bus. Rev. 2008, 17, 188-193. [CrossRef]

21. Fei, X. Caxù Géjú; WenYuan Publishing Co.: Beijing, Chain, 2015; Volume 6, pp. 46-47. (In Chinese)

22. Choi, Y.; Jin, J. Is the Web Marketing Mix Sustainable in China? The Mediation Effect of Dynamic Trust. Sustainability 2015, 7, 13610-13630. [CrossRef]

23. Wang, Y.; Zhao, Z.J. Performance of Public-Private Partnerships and the 592 Influence of Contractual Arrangements. Public Perform. Manag. Rev. 2018, 41, 177-200.

24. Air Quality with PM. Available online: https://m.blog.naver.com/PostView.nhn?blogId=gumdansan $21 \& \operatorname{logNo=}$ 220696620560\&proxyReferer=http\%3A\%2F\%2Fwww.google.com\%2Furl\%3Fsa\%3Di\%26rct\%3Dj\%26q\%3D\%26esrc\% 3Ds\%26source\%3Dimages\%26cd\%3D\%26ved\%3D2ahUKEwi6_Y7cicjaAhWMmJQKHX2xCXUQjxx6BAgAEAI\% 26url\%3Dhttp\%253A\%252F\%252Fm.blog.naver.com\%252Fgumdansan21\%252F220696620560\%26psig\% 3DAOvVaw3GamVwhOfutk6u_jor-Dj0\%26ust\%3D1524286961482517 (accessed on 17 April 2018).

25. Jin, L. The Asian Infrastructure Investment Bank Inaugural Ceremony. Available online: https://www.aiib. org/en/news-events/news/2016/20160119_001.html (accessed on 1 May 2018).

26. Choi, Y.; Lee, E. Optimizing Risk Management for the Sustainable Performance of the Regional Innovation System in Korea through Metamediation. Hum. Ecol. Risk Assess. 2009, 15, 270-280. [CrossRef]

27. Savas, E.S. Privatizing the Public Sector: How to Shrink Government; Chatham House Publishers: London, UK, 1982.

28. Wong, M. Guanxi and its role in business. Chin. Manag. Stud. 2007, 1, 257-276. [CrossRef]

(C) 2018 by the author. Licensee MDPI, Basel, Switzerland. This article is an open access article distributed under the terms and conditions of the Creative Commons Attribution (CC BY) license (http://creativecommons.org/licenses/by/4.0/). 